\title{
A esposa que suga a vida sem pudor e o corno que morre para o mundo
}

\section{Cecilia Inés Luque}

\section{Universidad Nacional de Córdoba / Centro de Investigaciones "María Saleme de Burnichon"}

Resumo: $\mathrm{O}$ imaginário patriarcal do amor romântico foi usado no século XIX para naturalizar a divisão sexual do trabalho própria do capitalismo industrial. Segundo esse discurso, o amor encaminha a sexualidade para o vínculo interpessoal por excelência que é o matrimônio e a dignifica pondo a procriação ao serviço de Deus e a Pátria. No século XX, as classes médias brasileiras ainda achavam que, sem o controle da sexualidade feminina, as mudanças trazidas pela modernização causariam o caos social. A partir da década de 1970, sob o influxo dos movimentos de mulheres e os feminismos, a sexualidade das mulheres transformou-se novamente em um tema de preocupação social no Brasil e debateu-se muito seu direito ao prazer desvinculado da procriação. Nesse contexto de controvérsia, podem-se encontrar em alguns textos literários os indícios de como a crise das mulheres insatisfeitas com o matrimônio burguês convencional causou necessariamente a crise da masculinidade heteropatriarcal, na medida em que o desejo das esposas de explorar sua erogeneidade coloca em questão os pilares do imaginário com o qual os maridos definem e praticam sua masculinidade. Uma leitura queer desses textos - um olhar contra a luz - permite perceber os indícios da agonia simbólica do Macho, causada pela ferida infligida à sua masculinidade pelo surgimento dos feminismos e pelos movimentos de mulheres.

Palavras-chave: matrimônio burguês; desejo feminino; crise da masculinidade 


\begin{abstract}
The patriarchal imaginary of romantic love was used in the 19th century to naturalize the sexual division of labor typical of industrial capitalism. According to this discourse, love steers sexuality towards the human relation par excellence that is marriage and, in doing this, dignifies sexuality by putting procreation at the service of God and Country. In the 20th century, Brazilian middle classes still believed that, without putting feminine sexuality under control, the changes brought forth by Modernity would cause social chaos. Since the 1970s, under the influence of women's movements and feminisms, women's sexuality became again an issue of social concern in Brazil; furthermore, women's right to enjoy pleasure without risking pregnancy was hotly debated. In this context of controversy, it is possible to find in some literary texts signs of how the crisis of women unsatisfied with a conventional bourgeois marriage necessarily caused the crisis of heteropatriarchal masculinity, given that the wives' desire of exploring their erogeneity questions the foundations of the imaginary with which the husbands define and practice their masculinity. A queer reading of these texts - a reading against the grain - allows us to perceive the signs of the Macho Man's symbolic agony, brought about by the injury inflicted on his masculinity by the emergence of feminisms and women's movements.
\end{abstract}

Keywords: Bourgeois marriage; feminine desire; masculinity crisis

It is quite simply not in men's interest to change too much, unless women force them to.

Lynne Segal ${ }^{1}$

No Brasil contemporâneo, o imaginário do amor conjugal romântico² continua sendo um dos discursos que governam o que pode ser pensado e dito sobre "a mulher" e "o homem". Tal imaginário constitui o discurso patriarcal e burguês usado no século XIX para naturalizar a divisão sexual do trabalho própria do capitalismo industrial. Segundo esse discurso, o amor encaminha a sexualidade para o vínculo interpessoal por excelência - o matrimônio - e a dignifica, pondo a procriação ao serviço de Deus e da Pátria. Assim sendo, a afetividade desvinculada do desejo sexual transforma-se na característica principal da 
"boa mulher", digna de conseguir o amor de um "homem bom" e de converter-se em esposa e mãe.

Pois bem, a partir de 1940, os processos de industrialização e urbanização do Brasil, assim como a incipiente inserção da mulher no âmbito público do trabalho assalariado e da educação formal, favoreceram a aparição de espaços de interação onde homens e mulheres podiam socializar de forma menos ritualizada e menos vigiada. Ao mesmo tempo, os novos modos de recreação, como os filmes do cinema hollywoodiano e as revistas que exibem seus artistas, apresentavam como modelos glamorosos e desejáveis comportamentos sociais inéditos até ao momento (vestir de certa maneira, beber álcool, fumar, beijar-se na boca). Tais mudanças afetaram a forma de viver e de pensar as relações amorosas, especialmente em cidades como o Rio de Janeiro e São Paulo; mesmo que as elites brasileiras continuassem achando que a "honra" das mulheres era a base da família e a força moralizadora da nação e que, sem controle da sexualidade feminina, as mudanças trazidas pela modernização causariam a dissolução da família, um aumento brutal da criminalidade e o caos social. Nesse contexto, os meios de comunicação de massa ajudaram a que cada aspecto do comportamento feminino dentro e fora do lar e cada aspecto das relações amorosas - especialmente os adultérios e os "crimes passionais" - se transformassem em temas recorrentes da opinião pública; do mesmo modo, o viés dado a tais temas contribuiu ao disciplinamento do desejo feminino. Por exemplo, os textos destinados às jovens leitoras mostravam heroínas assexuadas e romances platônicos nos quais se exaltavam as figuras da jovem virginal, a esposa abnegada e a dona de casa diligente; enquanto os redatores da seção policial dos jornais encarregavam-se de criminalizar os desejos e as atividades sexuais das mulheres sob a figura recorrente da esposa infiel que leva o homem traído a cometer assassinatos.

Nos anos setenta, sob o influxo dos movimentos de mulheres e os feminismos, a sexualidade das mulheres transformou-se novamente em um tema de preocupação social e debateu-se muito seu direito ao prazer desvinculado da procriação. Por exemplo, Rose Marie Muraro, uma das pioneiras do movimento feminista no Brasil na década de 1970, publicou Sexualidade da mulher brasileira, corpo e classe social no Brasil (1983), onde 
apresenta os resultados de sua pesquisa de campo em vários estados do Brasil sobre como é vivenciada a sexualidade das mulheres, tomando em conta sua situação de classe. A publicação do livro gerou uma enorme confusão, já que trouxe à tona temas tabus e proibidos naquela época. Alguns anos antes, em 1963, Betty Friedan abrira a disputa sobre o assunto com seu polêmico livro A mística feminina, no qual analisava o "problema mal formulado" ou "mal sem nome" que acometia as mulheres obrigadas a serem donas de casa, mães e esposas perfeitas. A controvérsia propagada por esse livro também chegou ao Brasil, quando Rose Marie Muraro publicou sua tradução em 1971 e trouxe, depois, a própria Friedan. Ambas as mulheres mantiveram uma intensa agenda no Brasil, diante da qual a imprensa reagiu ridicularizando o feminismo, tergiversando as palavras de Friedan nas reportagens que publicavam e desprestigiando sua pessoa através de comentários sobre sua vida íntima.

Nesse contexto de intenso debate, surgiram controvérsias sobre o que significa "ser mulher" e "ser homem" para a classe média brasileira. ${ }^{3}$ Proponho a leitura de dois textos literários à luz de tais controvérsias: o conto "I love my husband" (1980), de Nélida Piñon, e a crônica "A dama do lotação" (1961?), ${ }^{4}$ de Nelson Rodrigues. Trata-se de dois textos bem diferentes: o primeiro, escrito por uma mulher com consciência de gênero, o segundo, escrito por um machista recalcitrante; um é uma fantasia metafórica das saudades do matriarcado de uma mulher, o outro, um relato admonitório sobre os perigos de o homem não cuidar a honra de sua mulher. Contudo, os dois abordam o lado escuro da vida conjugal nos tempos do feminismo de uma maneira interessante: ambos refratam ${ }^{5}$ a crise sofrida necessariamente pelos homens quando as mulheres se retiram excentricamente ${ }^{6}$ das posições socioeconômicas ocupadas historicamente, sendo esse deslocamento o que coloca em questão os pilares do imaginário com o qual os homens definem e praticam sua masculinidade.

O conto "I Love my husband" gira em torno do monólogo interior de uma mulher que descobre e analisa sua profunda insatisfação como esposa e dona de casa. Uma clara alusão intertextual aos livros sobranceiros de Gilberto Freyre permite situar socioeconômica e culturalmente a este casal em uma classe média herdeira dos projetos da burguesia liberal 
de fins do século XIX, e para a qual o amor conjugal e a família moderna são o eixo da organização da Nação: "A mim também me saúdam por alimentar um homem que sonha com casas grandes, senzalas e mocambos, e assim faz o país progredir" (Piñon 2000: 451). ${ }^{7}$

Um belo dia, a protagonista percebe uma diferença entre a imagem que os outros têm dela e aquilo que ela sente, descobre que essa diferença provoca-lhe uma profunda inquietação e identifica dois elementos chave para esse desassossego: por um lado, a obrigação social de reprimir seus desejos sexuais para manter sua imagem de "boa mulher"; por outro, a ingratidão do marido, que não reconhece o aporte do trabalho doméstico da esposa ao progresso do casal e do país. Começa ela, então, "a ambicionar que maravilha não seria viver ... antes que este tempo ... ditado pelo homem que dizemos amar" (idem: 452).

Ora, no mundo do Pai, um homem supostamente ideal teria "pedido de joelhos o [seu] amor" (idem: 453), mas, depois de obtê-lo, trancou-a na jaula dourada da felicidade doméstica num "edifício de dezoito andares e três portarias" (ibidem) e amarrou-lhe as mãos para virar dono absoluto do corpo dela. Entretanto, em um passado - porém, ainda possível - mundo da Mãe, a mulher poderia deixar "Clark Gable amarrado numa árvore, lentamente comido pelas formigas" e viver uma "aventura africana" que acordaria "a febre que estava em [suas] entranhas" (ibidem), livraria suas mãos para ela tocar o próprio sexo e far-lhe-ia descobrir que "havia outras peles igualmente doces e privadas, cobertas de pelo felpudo, e [que] com a ajuda da língua podia lamber-se o seu sal" (idem: 452). Em outras palavras, a protagonista-narradora coloca as relações entre os sexos através de uma estética discursiva e de um marco teórico que remetem ao feminismo da diferença: ${ }^{8}$ os desejos femininos - pulsionais, indisciplinados, apaixonados - têm sido historicamente reprimidos pelo falogocentrismo patriarcal e devem ser liberados; portanto, a tarefa da mulher é a "experimentação sistemática dos funcionamentos do corpo, uma interrogação precisa e apaixonada de sua erogeneidade" (Cixous 2004: 18; tradução minha).

Pois bem, quando a mulher tenta falar com o marido sobre seus desejos reprimidos, o que se estabelece entre eles não é uma comunicação, mas um diferendo; isto é, um conflito entre duas partes, dirimido no idioma de uma delas, idioma com o qual se invisibiliza o dano sofrido pela outra parte no conflito: ${ }^{9}$ 
através da certeza do meu amor, proclama que não faço outra coisa senão consumir o dinheiro que ele arrecada no verão. Eu peço então que compreenda minha nostalgia por uma terra antigamente trabalhada pela mulher, ele franze o rosto como se eu lhe estivesse propondo uma teoria que envergonha a família e a escritura definitiva do nosso apartamento. [...] 0 que mais quer, mulher, não lhe basta termos casado em comunhão de bens? [...] deixe-me progredir, mulher. Como quer que eu fale de amor quando se discutem as alternativas econômicas de um país em que os homens para sustentarem as mulheres precisam desdobrar um trabalho de escravo. (Piñon 2000: 452)

A mulher, então, muda de assunto e decide falar sobre progresso, o outro motivo de sua inquietação. Porém, quando ela questiona a magra contribuição que lhe é permitida, limitada a cuidar do homem "que sonha com casas-grandes, senzalas e mocambos", mas "constrói o seu mundo com pequenos tijolos" (idem: 451), o marido ofende-se e constrangese pelo "repúdio a um ninho de amor, segurança, tranquilidade, [...] [à] maravilhosa paz conjugal" (idem: 453). A perturbação do marido é tão grande que fá-lo soltar um choro "discreto, porque o [s]eu orgulho não lhe permite o pranto convulso, este sim, reservado à [...] mulher" (idem: 453). Contrita e envergonhada por ter ferido a honra do marido, a esposa desiste de "conquistar outra pátria, nova língua, um corpo que sugasse a vida sem medo e pudor" e retoma a "submissão ao cotidiano feliz, que nos obriga a prosperar a cada ano" (idem: 455).

"I love my husband" apresenta, através de uma narrativa metafórica, os custos para a mulher da postergação de seus desejos e a submissão aos mandatos de uma sociedade heteropatriarcal e capitalista, e por isso o conto se tornou um clássico do feminismo brasileiro. Contudo, existem nesse texto umas breves linhas que costumam passar despercebidas para a crítica feminista e, portanto, não são devidamente analisadas: as cinquenta e cinco palavras dedicadas a insinuar a crise sofrida pelo homem heteropatriarcal quando a mulher começa a tomar consciência de gênero e a fazer algo a respeito: "você, marido, [...] só porque mencionei esta palavra que te entristece [futuro], [...] você começa a chorar discreto, porque o teu orgulho não lhe permite o pranto convulso, este sim, reservado à minha condição de mulher? [...] Será que apagando o futuro agora ainda há tempo de salvar-te?" (idem: 453). Os estudos de gênero demonstraram que o 
conceito de "mulher" não é definido por meio de uma série fixa de atributos, mas através de uma posição relativa à posição de "homem" - e vice-versa - em uma rede de relações de poder marcada sociohistoricamente; portanto, quando algum dos elementos que constituem a posição relativa "mulher" é modificado (no caso, ser "livre para viver a vida a que ele apenas tinha acesso" [idem: 452] e ter um futuro próprio), resulta impossível para a posição "homem" permanecer inalterada. Mas os homens heteropatriarcais têm grandes dificuldades para aceitar tal "vice-versa" ou pensar sequer nisso, porque fazê-lo implica colocar em crise o conceito de masculinidade com o qual definiram suas subjetividades até o momento. Para os homens heteropatriarcais, o reclamo das mulheres a partir de um posicionamento de gênero muda o idioma no qual estiveram dirimindo o diferendo entre os sexos; e isso desconcerta-os.

O conto de Piñon focaliza, mesmo brevemente, a crise de masculinidade sofrida pelos homens quando eles perdem a agência social. A "honra" do homem heteropatriarcal, seu prestígio, consiste em ser um bom pater familias: alguém capaz de satisfazer sexual e socioeconomicamente sua esposa. ${ }^{10} \mathrm{~A}$ esposa do conto é consciente disso, razão pela qual desiste de falar de seu "desatinado" apetite sexual e de suas vontades por "trabalhar fora, pagar as miudezas com [s]eu próprio dinheiro" (idem: 456): sabe que nem seu marido nem o macho burguês “suportaria[m] o peso dessa confissão” (ibidem).

Por sua parte, Nelson Rodrigues, um ícone da temática familiar burguesa no Brasil, transforma a crise da masculinidade em tema central de "A dama do lotação". Sua crônica inverte o esquema da típica narrativa da secção policial dos jornais: em lugar do drama do marido traído que lava sua honra matando a esposa infiel, encontramos o sainete do corno que "morre para o mundo"; 11 em lugar da costumeira criminalização da sexualidade feminina, a (involuntária) admissão da crise de masculinidade do macho burguês.

O texto de Rodrigues combina o efeito da verdade da crônica com o caráter jocoso e as personagens tipicamente populares do sainete, para oferecer uma representação satírica dos costumes sexuais da classe média urbana brasileira. ${ }^{12}$ A sátira é uma prática moralizante que marca o exemplo a seguir através da zombaria denegritória de tudo aquilo que "não deve ser" e "não se deve fazer"; assim, o riso reforça e legitima o sistema 
hegemônico. "A dama do lotação" ridiculariza a pusilanimidade de Carlinhos, um marido incapaz de punir "como é devido" a desavergonhada atividade sexual de sua esposa Solange e permite, assim, a mácula de sua honra de homem.

No início do relato, Carlinhos aparece como o típico macho patriarcal que zela por sua esposa e assegura para seu P/pai: "Se for verdade o que eu desconfio, meu pai, mato minha mulher!" (Rodrigues 1992: 216). Ele, inclusive, interroga Solange aos gritos e a ponta de pistola. Porém, quando Carlinhos descobre que essa mulher "doce-de-coco [que] sugeria nos gestos e mesmo na figura fina e frágil qualquer coisa de extraterreno" (idem: 217), "precisava escapar de casa" (idem: 219) para viver sua sexualidade livremente, o homem termina tão afrontado e desconcertado como o esposo de "I love my husband". Desconcertao o fato de essa mulher de pureza etérea poder ter um apetite sexual desenfreado, porque, para o imaginário romântico, a "boa mulher" é angelical e assexuada. Afronta-o o fato de Solange fazer sexo indiscriminadamente com amigos e desconhecidos, pois, dessa maneira, Carlinhos perde sua honra de macho: ou seja, o reconhecimento de sua virilidade por parte de seus pares. Resulta interessante notar como, com a breve menção do "mecânico, de macacão azul" (idem: 219) com o qual Solange fizera sexo, a narração introduz à equação o fator de classe, indicando superficialmente o vínculo entre afetos e condições materiais de existência; o que será problematizado apenas na década de 1980 (lembremos da pesquisa de Rose Marie Muraro) e que estender-se-á à compreensão de como os homens vivem sua virilidade mais de uma década depois, quando os Estudos da Masculinidade, os Estudos Queer e os movimentos de homens antipatriarcais aplicarem-se a "desuniversalizar" e "desbiologizar" o masculino.

A crônica termina com a imagem ridícula da esposa velando o marido vivo, deitado na cama: mesmo que Solange retorne todos os dias a casa para cumprir religiosamente seus afazeres domésticos, Carlinhos não consegue suportar o peso dessa confissão - como assim também não pôde o esposo do conto de Piñon - e opta por uma saída insólita: "Morri para o mundo" (idem: 220). Rodrigues remata com um final cômico a história que prometia um desfecho trágico, para condenar através do riso a falta de hombridade de Carlinhos. Contudo, uma leitura queer da crônica -um olhar contra a luz - permite recuperar sua 
dimensão dramática: ou seja, a rachadura do patriarcado causada pelos desejos das mulheres por sugar a vida sem pudor e o consequente deslocamento excêntrico de sua posição de "doce-de-coco" e anjo do lar.

De fato, tanto a morte absurda na vida de Carlinhos, quanto Clark Gable comido pelas formigas em "I love my husband", funcionam como indícios da agonia simbólica do Macho heteropatriarcal, causada pela ferida infligida à "honra" masculina pelo surgimento dos feminismos e pelos movimentos de mulheres. Claro está, trata-se de uma agonia sem fim visualizável: na atualidade, mais de trinta anos depois da publicação destes relatos, as feministas argentinas continuam reclamando pela "muerte al macho" ["morte ao macho"] em passeatas e grafiti. ${ }^{13}$ Mesmo assim, ela refrata, modesta e quase imperceptivelmente, as causas do "início do fim" do patriarcado burguês.

Em modo de conclusão, "I Love my husband" e "A dama da lotação" apresentam posicionamentos de gênero diametralmente opostos (Nélida advoga pelo feminismo da diferença, Nelson fustiga os machos burgueses para eles reafirmarem sua autoridade patriarcal); porém, ambos os relatos tocam indiretamente em um assunto ainda não consolidado como problemática, pois quase não existiam repertórios discursivos com os quais "pensá-lo" desse modo: isto é, a crise da masculinidade burguesa diante da pressão dos efeitos da emancipação feminina. 


\section{NOTAS}

${ }^{1}$ A citação pertence ao livro Slow Motion: Changing Masculinities, Changing Men (1990), de Lynne Segal.

20 amor conjugal, no contexto estético-político do romantismo latino-americano, é entendido como uma sexualidade produtiva na esfera doméstica; portanto, a história de amor deve, naturalmente, desembocar no matrimônio e na formação de uma família.

3 Valham os dois exemplos a seguir: no artigo "O que é uma mulher livre?", publicado na seção "A Arte de Ser Mulher" da revista Claudia em julho de 1971, a jornalista e psicanalista Carmen da Silva manifestou seu protesto pelo tratamento dado pela imprensa brasileira a Betty Friedan. Por outro lado, as crônicas policiais de Nelson Rodrigues publicadas de 1951 a 1961 na seção "A vida como ela é" dos jornais cariocas Última Hora e Diário da Noite estavam dirigidas principalmente a leitores homens e sua temática predominante era a tragédia desencadeada pelos desejos desgovernados das mulheres e sua consequente infidelidade.

${ }^{4}$ Não disponho da data exata da publicação. As crônicas foram publicadas entre 1951 e 1961, e o seu cenário era o Rio de Janeiro dos anos 50.

${ }^{5}$ A refração como categoria analítica constitui uma analogia do fenômeno físico no qual um raio de luz desviase de seu curso anterior ao passar de um meio a outro de diferente densidade (como ocorre com a imagem de um lápis quando semi-submerso em um copo d'água). No nível representacional, a refração é um processo pelo qual um texto integra uma problemática presente em um discurso social prévio ("a luz") e re(a)presenta-a, ainda que com distorções devidas às características intrínsecas de seu próprio discurso (duas diferentes "densidades"). Pensar as representações literárias como refração de problemáticas sociais permite superar a dicotomia realidade/fiç̧ão implícita na categoria "reflexo". Cf. Refracting The Canon in Contemporary Literature and Film, Ed. Susana Onega and Christian Gutleben, Rodopi, Amsterdam and New York, 2004.

${ }^{6}$ Sujeito excêntrico é aquele em uma relação paradoxal com a norma, devido a ter sido constituído como sujeito pela interpelação dessa norma, mas tendo se distanciado dela e criticando-a, após tomar consciência das desigualdades de poder e saber sustentado por tal norma (cf. Lauretis 2000).

7 Casa Grande e Senzala (1933) apresenta a importância da estrutura social e moral da casa grande na formação sociocultural brasileira; Sobrados e Mocambos (1936) expõe as transformações do patriarcado rural resultantes das pressões dos processos de modernização.

${ }^{8} \mathrm{O}$ feminismo da diferença foi desenvolvido simultaneamente nos Estados Unidos, na França, na Itália e na Espanha dos anos setenta por pensadoras como Hélène Cixous, Luce Irigaray, Carla Lonzi, Luisa Muraro, Virginia Sendón de León, como um posicionamento radical oposto ao reformismo do feminismo da igualdade. Cada pensadora e cada grupo, em cada país, colocou a ênfase em diferentes tópicos (desejo, maternidade, 
lesbianismo, etc.), baseadas em uma variedade de marcos teóricos (psicanálise, semiótica, etc.). Também não houve homogeneidade nem consenso na hora de utilizar o termo "diferença". A vertente francesa parte da reivindicação da diferença da mulher, sobretudo em termos de alteridade face à cultura patriarcal, e utiliza a exploração do inconsciente e da erogeneidade como meio privilegiado para reconstruir uma identidade autenticamente feminina, sem vestígios das deformações impostas pela definição falocêntrica de "A Mulher". Neste trabalho refiro-me a essas ideias e especificamente às propostas de Cixous.

${ }^{9}$ Cf. Jean François Lyotard, Le Différend (1983), citado en Collin 1996: 13.

${ }^{10} \mathrm{~A}$ virilidade (potência vinculada à sexualidade) e o ser bom provedor da família (agência, competências que lhe permitem agir com eficácia e autoridade na sociedade), habilitam o indivíduo para ele ser reconhecido como "homem". Se alguma dessas habilidades, ou ambas, forem contrariadas, a hombridade do indivíduo verse-á questionada.

${ }^{11}$ Expressão que utiliza a personagem do marido traído na crônica de Rodrigues para explicar a sua situação.

${ }^{12}$ As personagens da crônica são de "ótima família”, na qual "havia de tudo: médicos, advogados, banqueiros e, até, ministro de Estado" (Rodrigues 1992: 216-217).

${ }^{13}$ Este slogan surgiu durante a multitudinária passeata realizada, em forma simultânea, em oitenta cidades da Argentina em 2015 contra a violência de gênero e o número alarmante de feminicídios acontecidos no país nos meses precedentes. As passeatas foram organizadas por coletivos de mulheres sob a divisa "Ni una menos" [Nem uma a menos], a qual resume a ideia principal da convocatória e os fins do movimento; os coletivos exigem ao Estado instrumentos que garantam a proteção das vítimas de violência de gênero e uma maior discussão sobre o tema através de estratégias educacionais para todos os níveis de ensino. Nesse contexto, os slogans "muerte al macho" [morte ao macho] e "machete al machote" [facão para o machão], ainda hoje são gritados nas passeatas, grafitados nos muros, empregados em memes feministas como metáforas de forte impacto para exprimir um dos objetivos teórico-políticos do movimento "Ni una menos": dar visibilidade e desativar a construção hegemônica da masculinidade que naturaliza e legitima a violência contra as mulheres. O movimento tem sido reproduzido em outros países da região como Uruguai, Chile, Colômbia e Venezuela. 


\section{Bibliografia}

Bastos, Ligia Maria Thomaz (2014), “A imbricação do patriarcado em I love my husband, de Nélida Pinõn". Anais do II Colóquio Internacional Literatura e Gênero. Relações entre gênero, alteridade e poder. Piauí, Brasil, 1-7.

Cixous, Hélène (2004), Deseo de Escritura, Barcelona, Reverso Ediciones SL.

Collin, Françoise (1996), "Praxis de la diferencia: Notas sobre lo trágico del sujeto", Mora n. 1, 2-17.

Fonseca, Carlos (2006), "La De-construcción de la Masculinidad por las Manifestaciones de la Diversidad Sexual en el Occidente Contemporáneo", La Manzana vol. 1, no. 1, EneroMarzo, <http://www.estudiosmasculinidades.buap.mx/paginas/frames.htm> (último acesso em 16/02/2015).

García García, Antonio (2009), Modelos de identidad masculina: Representaciones y encarnaciones de la virilidad en España (1960-2000), Tesis Doctoral. Universidad Complutense de Madrid, Madrid, España, <http://eprints.ucm.es/9537/1/T31015.pdf> (último acesso em 15/03/2014).

García-Obregón, Omar (2011), "El arte de narrar la memoria femenina: La mujer como agente en la parodia de la normatividad de género", Revista Brasileira do Caribe, São Luis Br, Vol. XII, n.ํㅜ 23, Jul-Dez., 165-190.

Lauretis, Teresa de (2000), Diferencias. Etapas de un camino a través del feminismo, Madrid, horas y HORAS.

Piñon, Nélida (2000). "I love my husband", Os Cem Melhores Contos Brasileiros do Século, Seleção Ítalo Moriconi, Rio de Janeiro, Editora Objetiva, 451-456.

Preciado, Beatriz (2012), “Queer': historia de una palabra”, Parole de Queer, Blog. <http://paroledequeer.blogspot.mx/2012/04/queer-historia-de-una-palabra-por.html> (último acesso em 03/03/2014). 
Rodrigues, Nelson (1992), "A dama do lotação", A vida como ela é... o Homem Fiel e Outros Contos, São Paulo, Companhia das Letras, 216-220.

Segal, Lynne (1990), Slow Motion: Changing Masculinities, Changing Men, New Brunswick, Rutgers University Press.

Zechlinski, Beatriz Polidori (2006), Imagens do casamento e do amor em Nelson Rodrigues: Um estudo das representações de gênero na literatura publicada em jornal entre 1944 e 1961, Tesis de Maestría, Historia, Universidade Federal do Paraná, <http://www.poshistoria.ufpr.br/documentos/2006/Beatrizpolidorizechlinski.pdf> (último acesso em 19/10/2010).

Cecilia Inés Luque doutorou-se em Literatura e Linguística Hispânica e Luso-Brasileira, em 1994, pela University of Minnesota, EUA. Atua no ensino das literaturas latino-americanas na graduação e pós-graduação, com uma perspectiva teórica que reúne os Estudos de Gênero, os Estudos Culturais e os Estudos Pós-Coloniais. É membro do corpo docente do Doutorado em Gênero do Centro de Estudios Avanzados da Universidad Nacional de Córdoba desde 2010 e membro da Comissão Acadêmica do Doutorado em Ciências do Linguagem da Facultad de Lenguas da mesma universidade desde 2015. 